\title{
Lowering Gasifier Tars and Particulates Using Heated Dololmite Catalyst and a Particulate Filter
}

\author{
Christopher O. Akudo, Beatrice G. Terigar, Chandra S. Theegala*
}

Department of Biological and Agricultural Engineering, Louisiana State University, Baton Rouge, USA.

Email: *CTheegala@agcenter.lsu.edu

Received December 21 $1^{\text {st }}$, 2011; revised January 31 ${ }^{\text {st }}, 2012$; accepted February $7^{\text {th }}, 2012$

\begin{abstract}
For this study, a fixed-bed, down-draft gasifier was designed to investigate the effect of a dolomite catalytic bedon tar removal. Pine pellets and wood chips (cypress) were used to produce syngas from the down-draft gasifier. For the gas conditioning, a combination of a heated dolomite (bed temperature at $850^{\circ} \mathrm{C}$ for catalytic cracking of tars) and a particulate filter (for particulate removal) was used. Investigation of temperature effects on dolomite activity between $650^{\circ} \mathrm{C}$ and $950^{\circ} \mathrm{C}$ bed temperatures, showed optimum catalytic efficiency at approximately $850^{\circ} \mathrm{C}$. At the optimum conditions, gravimetric tar and particulate concentrations in syngas produced from pine pellets were $0.85 \mathrm{~g} / \mathrm{Nm}^{3}( \pm 0.16)$ and $4.75 \mathrm{~g} / \mathrm{Nm}^{3}( \pm 0.07)$, respectively before gas conditioning, and $0.09 \mathrm{~g} / \mathrm{Nm}^{3}( \pm 0.02)$ and $2.01 \mathrm{~g} / \mathrm{Nm}^{3}( \pm 0.13)$, respectively after gas conditioning. Syngas from wood chips contained $1.63 \mathrm{~g} / \mathrm{Nm}^{3}( \pm 0.45)$ and $3.84 \mathrm{~g} / \mathrm{Nm}^{3}( \pm 1.16)$ of tars and particulates, respectively before gas cleaning and $0.19 \mathrm{~g} / \mathrm{Nm}^{3}( \pm 0.02)$ and $2.27 \mathrm{~g} / \mathrm{Nm}^{3}( \pm 0.27)$ tars and particulates, respectively after gas conditioning. The combustible portion of the gas constituted carbon monoxide (12\% - $14 \%)$, hydrogen $(11 \%-12 \%)$, and methane $(\sim 2 \%)$. These results suggest that syngas produced from gasification of pine pellets and wood chips in a down-draft biomass gasifier can be effectively cleaned using a heated catalyst bed and a particulate filter. However, the benefits of gas conditioning will be offset by the need to maintain a heated catalyst bed for tar cracking.
\end{abstract}

Keywords: Gasification; Dolomite; Tars; Particulates; Syngas

\section{Introduction}

Biomass gasification is a thermo-chemical process that produces relatively clean and combustible gases through pyrolytic reaction. Depending on the gasifying agent (air, steam, oxygen) the raw gas produced at the gasifier exit has different compositions. The most commonly used agent at demonstration and commercial scale is air, with equivalence ratios of $0.2-0.3$ [1]. By use of air, the flue exit gas contains, on a volumetric basis, about $50 \% \mathrm{~N}_{2}$, $8 \%-20 \% \mathrm{H}_{2}$ and $\mathrm{CO}$ (each) and $2 \%-4 \% \mathrm{CH}_{4}$, with the remainders being $\mathrm{CO}_{2}$ and $\mathrm{H}_{2} \mathrm{O}$ [1]. This gas composition is mostly useful only for heat generation and electricity production. The exact gas composition at the gasifier exit in the process depends on other operating variables, and it has been well studied by different authors, at different operating scales and with different gasifiers [2-4]. In addition to these gases, a condensable mixture of organic compounds referred to as tars are formed [5]. Tars are undesirable because of the problems associated with condensation in the downstream processes where they form tar aerosols, and polymerization to form more com-

${ }^{*}$ Corresponding author. plex structures which can damage internal combustion engines, gas turbines, and other machinery. Therefore, the syngas needs to be cleaned of tars and other solid particles before it can be used in any fuel conversion device. The final gas quality dictates the end use or application suitability of the generated syngas.

There has been extensive research on tar elimination using catalysts that aid in the decomposition of the hydrocarbons found in tar. The most widely used catalysts are non-metallic oxides such as dolomite, olivine, magnesite, and zeolite [6]. Dolomite is a calcium magnesium ore with the general chemical formula $(\mathrm{CaMg})\left(\mathrm{CO}_{3}\right)_{2}$ that contains approximately $20 \% \mathrm{MgO}, 30 \% \mathrm{CaO}$, and $45 \% \mathrm{CO}_{2}$ on a weight basis [6]. The use of calcined dolomites in biomass gasification for tar cracking and removal has been the subject of interest in hot gas cleaning. Delgado and co-workers [7] studied the use of calcined dolomites in biomass gasification with steam. The catalytic decomposition of biomass tars using calcined dolomites was also reported by Devi and co-investigators [8].

Calcination of dolomite involves decomposition of the carbonate mineral, eliminating $\mathrm{CO}_{2}$ to form $\mathrm{MgO}-\mathrm{CaO}$. 
Complete dolomite calcination occurs at fairly high temperatures and is usually performed at $800^{\circ} \mathrm{C}-900^{\circ} \mathrm{C}$ [6] and restricts its effective use to these relatively high temperatures. Aznar and co-authors [9] performed experiments involving a bed of calcined dolomite placed after a biomass fluidized bed gasifier in which gasification was made with steam-oxygen mixtures to clean the raw syngas.

An alternative to the dolomite is the naturally occurring particles of olivine, which are a mineral containing magnesium, iron oxide and silica. Rapagna and co-workers [10] have indicated that the tar reforming activity of olivine was comparable to calcined dolomite. Olivine is advantageous in terms of its ability to withstand friction and does not easily break [8]. However, there is still ambiguity on the prospective use of olivine as a tar decomposing catalyst. Nickel based catalysts have been found to almost completely remove the tar and are also very effective for $\mathrm{NH}_{3}$ removal at temperatures above $800^{\circ} \mathrm{C}$ [11]. The main limitation of using nickel based catalysts is the tendency to lose their catalytic effect because of carbon fouling. This fouling effect occurs mainly when the catalyst is placed right after the gasifier. High tar concentration is one good example of the devastating effect on catalyst activity [12]. The use of a catalytic reactor downstream of the gasification reactor has proven to be a more effective approach to tar destruction [13]. From an energy balance point-of-view, the energy contained in the tars is fractional when compared to the energy content in the exiting gases. Due to these reasons, tar cracking is not aimed at enhancing the energy content of the gas, but primarily to improve the suitability of the generated syngas and to minimize problems with the downstream equipment. This fact was corroborated by Corella and co-workers [14], who concluded that there is almost no difference in the heating value of the gas produced after tar cracking. They indicated that the increase in the hydrogen production is compensated by a decrease in carbon monoxide, and there is hardly any change in methane production.

This study presents the results of further investigation of the use of dolomite for tar removal. The effect of catalytic bed temperature on tar removal was investigated. Also, since previous research focused on the use of dolomite in a fluidized bed system, its use in a fixed bed downdraft biomass gasifier is being explored in this paper.

\section{Experimental Section}

\subsection{Gasifier System Operation}

The fixed bed gasifier system used in this project consisted of a feeder unit, down-draft gasifier, gas flare chamber, temperature monitoring system, catalytic bed and a in house developed protocol $[15,16]$ for impurity sampling as shown in Figure 1. The gasifier feeder unit was designed to allow for batch feeding of biomass. Two $15 \mathrm{~cm}$ diameter knife-gate valves (with $68 \mathrm{~kg}$ rating) attached $45 \mathrm{~cm}$ apart on the $15 \mathrm{~cm}$ diameter metal feeding pipe was used as an airlock. This airlock allowed periodic feeding of biomass without the loss of internal pressure. The raw materials used were cypress mulch woodchips (less than $5 \mathrm{~cm}$ long, bought at local hardware stores) and pine pellets (Tractor Supply Co., Zachary, LA) that were less than $1.3 \mathrm{~cm}$ long and $0.6 \mathrm{~cm}$ diameter. The moisture content of the woodchips varied between $11 \%$ $17 \%$ during storage, while the pellets maintained fixed moisture content of 3.2\%. After the feed was weighed, it was manually loaded into the system. Using the gate valves and feed level detector, materials were reloaded during gasification. Six K-type thermocouples were connected to the wall of the furnace from top to bottom with approximately $7 \mathrm{~cm}$ distance between adjacent thermocouples. The majority of the gas that was produced from the gasifer (6 - 8 CFM) was flared in a flaring-unit. A small slip stream was drawn from the exiting

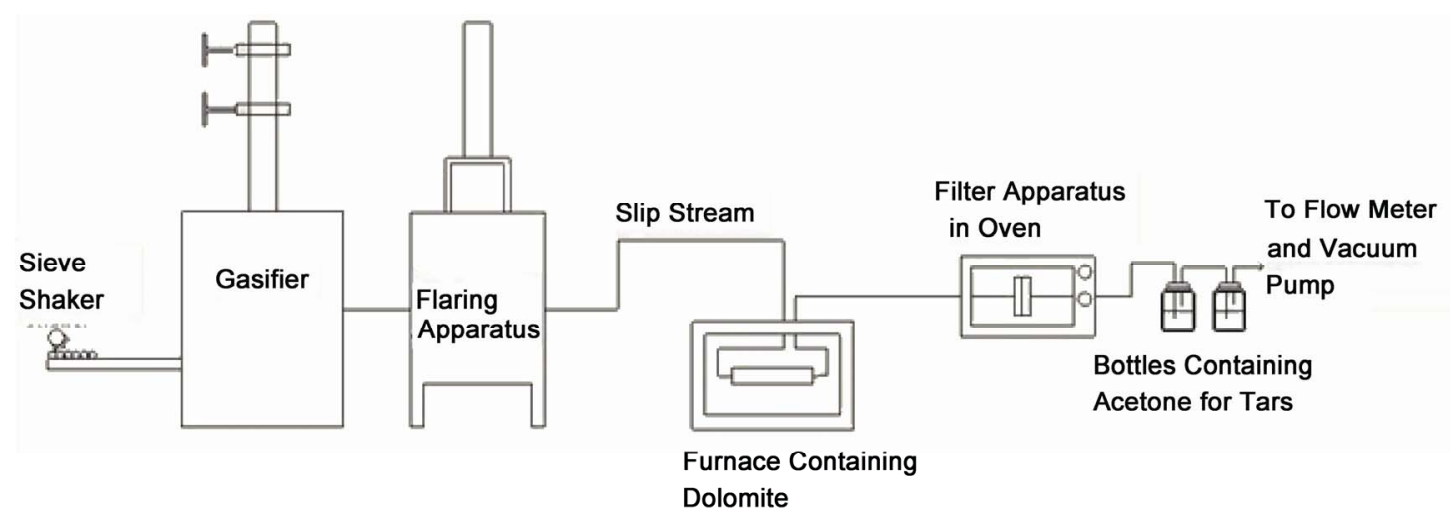

Figure 1. Gasification experimental setup consisted of a gasifier, flaring unit (for disposing the majority of the syngas), a slipstream connected to a catalyst bed (in a muffle furnace), a filter assembly (in a heated oven) and a tar quantification assembly (series of acetone bottles). 
syngas and was used for tar-cracking and particulate cleaning experiments as discussed below.

\subsection{Maintaining the Integrity of the Specifications Evaluation of the Gas Cleaning Component}

A small slip-stream of $94.4 \mathrm{~cm}^{3} / \mathrm{s}$ (0.2 CFM) was used for all gas cleaning experiments. The first component of the gas cleaning assembly consisted in a dolomite bed, set inside an electrically heated muffle furnace. The temperature of the dolomite bed was varied from $650^{\circ} \mathrm{C}$ to $950^{\circ} \mathrm{C}$ by altering the thermostat setting of the muffle furnace. A fixed-bed reactor (2.36 $\mathrm{mm}$ diameter) was used for all catalyst experiments. The fixed-bed had an internal diameter of $19 \mathrm{~mm}$ and length of $152.4 \mathrm{~mm}$ made from a steel pipe and was placed inside a muffle furnace. Catalyst depth in the pipe was $101.6 \mathrm{~mm}$ supported by wire mesh at both ends of the pipe. Prior to the experimentation involving dolomite, calcination of the dolomite was done at $850^{\circ} \mathrm{C}$ in a furnace for 2 hours.

The second component of the gas cleaning assembly included a glass fiber filter (Whatman: GF/F Cat No 1825 090) and a filter holder assembly placed inside an electrically heated oven for particulates removal and quantification. The filter assembly was heated to $250^{\circ} \mathrm{C}$ to prevent tar condensation on the filter paper. The particulates collected on the filter paper were quantified gravimetrically.

\subsection{Sampling and Analysis}

The syngas sampling was initiated after steady state temperatures were reached inside the gasifier. The steadystate point was also indicated by a self-sustainable flame in the flaring unit.As indicated earlier, the bulk portion of the produced syngas (6 - 8 CFM) was flared and all the gas conditioning experiments were conducted on a small $94.4 \mathrm{~cm}^{3} / \mathrm{s}(0.2 \mathrm{CFM})$ slip-stream of the generated syngas. The sampled gas was passed through insulated 0.32 cm copper tubing to the filter assembly, where the particulates were collected. The filter assembly in the oven was maintained at $250^{\circ} \mathrm{C}$, which prevented tars from condensing on the filter. The gas exiting the filter oven was passed through a series of four impinger bottles containing acetone, which collected the tars by dissolution (Figure 2). Passing the gas through a series of bottles ensured total collection of tars and number of bottles to be used in series was decided based on the amount of tars collected in the various impinger bottles during the trial runs.

Due to restrictions and depositions on the filter paper, the sample gas flow rate dropped from $94.4 \mathrm{~cm}^{3} / \mathrm{s}$ to 78.7 $\mathrm{cm}^{3} / \mathrm{s}$ after 30 minutes of sampling. The lowering of air flow was anticipated prior to running the experiments and appropriate adjustments were made during the quantification of tar and particulate concentrations.

The syngas exiting the acetone bottles was drawn through a volatile organic carbon absorber and a flow regulator before entering the vacuum pump. The gas exiting the vacuum pump was tested for syngas composition. The gas samples were drawn using a $10 \mathrm{ml}$ syringe with a $0.3 \mu \mathrm{m}$ syringe filter. The collected sample was then analyzed using a gas chromatograph (SRI, MG\#1) equipped with a $0.32 \mathrm{~cm}$ stainless steel silica gel-pack column and a thermal conductivity detector. An amount of $1 \mathrm{~mL}$ of gas sample was injected into the gas chromatography and ultra-high purity helium at a flow rate of 10 $\mathrm{mL} / \mathrm{min}$ was used a carrier gas $[15,16]$.

\section{Results and Discussion}

\subsection{Gasifier Temperature Profile}

The temperature of the gasifier during operation was continuously measured and recorded by a PC based data acquisition system. Temperature averages were calculated within a 30 seconds interval and average temperature profiles were created. Figure 3 shows a typical steady-state gasification temperature profile within the gasifier at various locations from the bottom grate. Temperature 1 represents the thermocouple immediately above the grate, and Temperature 2 to Temperature 6 represents the temperatures from thermocouples that

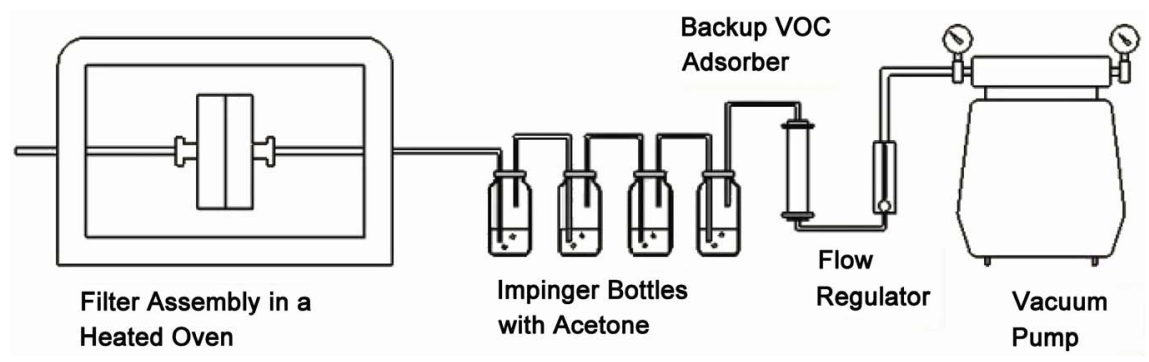

Figure 2. An in-house built particulate and tar quantification system was used for the present study. The particulate quantification unit consited of an stainless steel assembly placed inside an oven maintaiend at $250^{\circ} \mathrm{C}$. A series of four impinger bottles containing acetone collected the tars, and the syngas exiting the acetone bottles was drawn through a volatile organic carbon absorber and a flow regulator before entering the vacuum pump and tested for composition. 


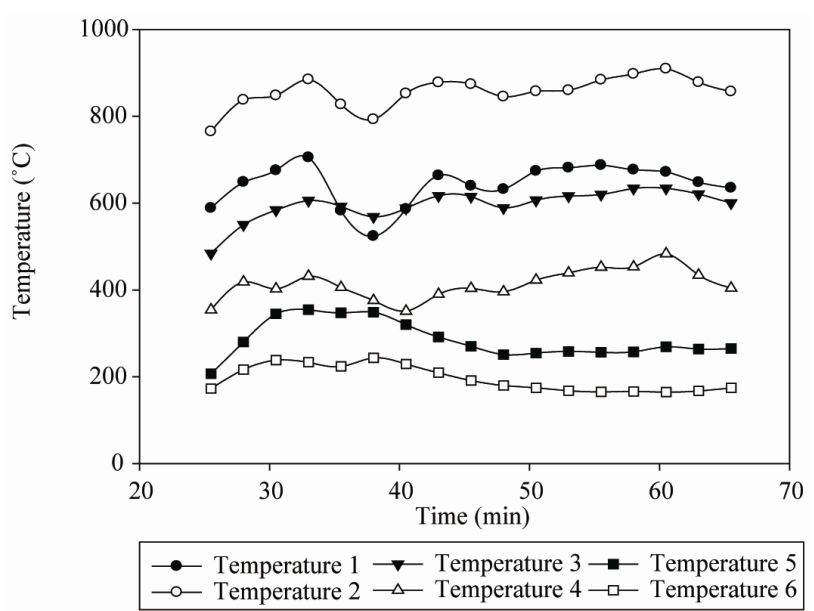

Figure 3. Temperature profile as gasification approaches steady state. Temperature 1 represents the thermocouple immediately above the grate, and Temperature 2 to Temperature 6 represents the temperatures from thermocouples that were placed approximately $7 \mathrm{~cm}$ higher than the preceding thermocouple.

were placed approximately $7 \mathrm{~cm}$ higher than the preceding thermocouple.

Based on the construction of the gasifier and the inlet ports (which were place between thermocouples 3 and 4), the highest steady-state temperatures (or oxidation zone) will be experienced by Temperature 2. All temperatures measured were relatively constant. However, Temperature 1 had a sharp decrease at about 35 min due to a malfunction of the grate which lead to a small accumulation of ash close to the thermocouple. This problem was promptly fixed resulting in a more accurate temperature profile.

Based on experimental observations, true gasification, as indicated by a self-sustainable flame in the flaring unit, occurs when the Temperature 2 temperatures exceed $700^{\circ} \mathrm{C}$ [17]. The high reactor temperature obtained also reduces the production of detectable tar species [18].

\subsection{Gas Composition and Heating Value}

The average yield of measured syngas components from wood chips and pine pellets are shown in Figure 4. The average concentrations of the combustible gases namely: carbon monoxide (CO), hydrogen $\left(\mathrm{H}_{2}\right)$, and methane $\left(\mathrm{CH}_{4}\right)$ obtained were within the limits reported in previous work [3]. However, the high percentage of nitrogen $\left(\mathrm{N}_{2}\right)$ present in the gas mixture could be explained by the fact that air was used as the gasification medium. The use of pure oxygen will result in higher percentages of the combustible gases; however, no additional efforts were made to lower the nitrogen content for this study. The attempt to minimize the air flow from the blower did not seem to have any noticeable effect on the gas composi-

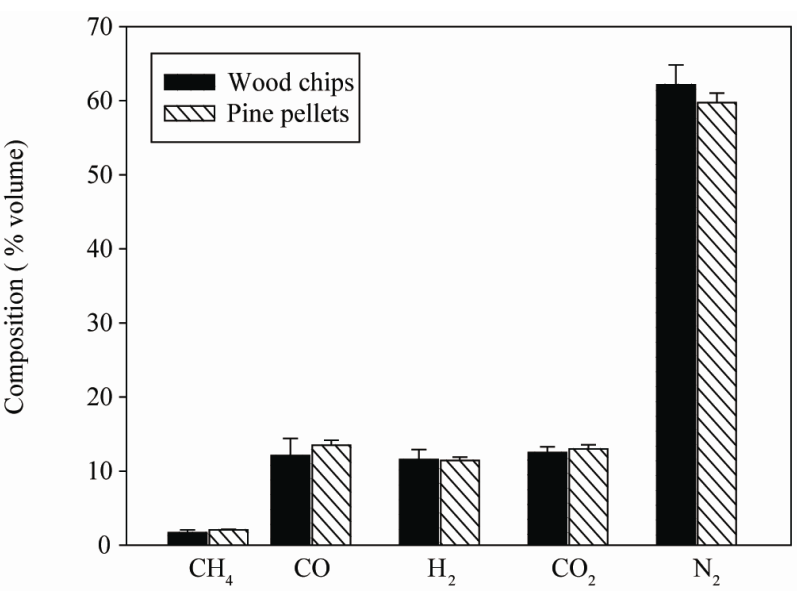

Figure 4. Volumetric concentration of combustible gases in the syngas from wood chips and pine pellets after gasification.

tion (data not shown) but rather reduced the velocity of the syngas flowing from the gasification chamber.

The heating value of a gas cannot be measured directly, but only with respect to a reference state. The most widely used is the Lower Heating Value (LHV), parameter thatdefines the potential energy available per unit volume of the biomass. This uses water vapor as its reference state. The heating value of the syngas was calculated from the concentration of combustible gases in the mixture.

Lower Heating Value $(\mathrm{LHV})=\% \mathrm{H}_{2} \times \mathrm{LHVH}_{2}+\% \mathrm{CH}_{4}$ $\times \mathrm{LHVCH}_{4}+\% \mathrm{CO} \times \mathrm{LHVCO}$

The heating values obtained were within the range of previous work using woodchips as raw materials. A comparison with data published on gasification with similar systems is presented in Table 1.

\subsection{Gravimetric Tar and Particulates}

The process of tar and particulate sampling was initiated only after the temperatures in the gasifier approached steady state and there was evidence of combustible gases produced, indicated by a self-sustaining flame. Figure 5

Table 1. Comparison of wood chips and pine pellets syngas composition from experimental results with literature published data.

\begin{tabular}{cccc}
\hline Parameters & $\begin{array}{c}\text { Published } \\
\text { Data [3] }\end{array}$ & $\begin{array}{c}\text { Experimental Results } \\
\text { Wood Chips }\end{array}$ & $\begin{array}{c}\text { Experimental Results } \\
\text { Pine Pellets }\end{array}$ \\
\hline $\mathrm{H}_{2}$ (\% Vol.) & $15-21$ & 11.56 & 11.44 \\
$\mathrm{CO}$ (\% Vol.) & $10-22$ & 12.09 & 13.49 \\
$\mathrm{CO}_{2}$ (\% Vol.) & $11-13$ & 12.50 & 12.98 \\
$\mathrm{CH}_{4}(\%$ Vol.) & $1-5$ & 1.70 & 2.05 \\
$\mathrm{~N}_{2}(\%$ Vol.) & $39-63$ & 62.16 & 59.73 \\
$\mathrm{LHV}\left(\mathrm{MJ} / \mathrm{Nm}^{3}\right)$ & $4.0-5.6$ & 3.38 & 3.67 \\
\hline
\end{tabular}




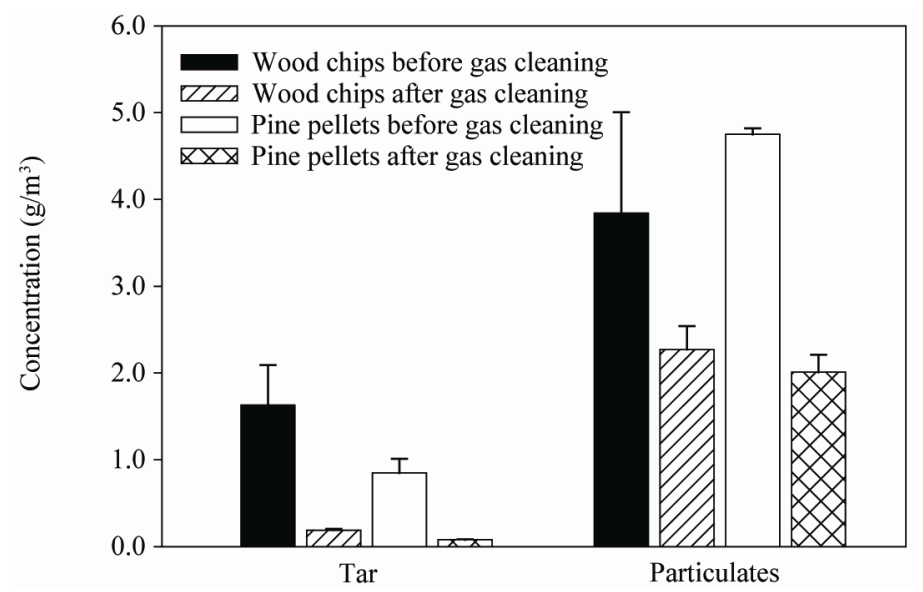

Figure 5. Concentration of tar and particulates in the wood chip and pine pellet syngas before and after the gas cleaning procedure.

shows the concentrations of tars and particulates both before and after gas conditioning in the syngas generated from wood chips and pine pellets.

A comparison of tar concentration in the syngas before and after treatment with dolomite at $850^{\circ} \mathrm{C}$ showed a significant decrease $(\mathrm{p}<0.05)$ of $90 \%$ and $92 \%$ for the wood chips and pine pellets respectively, after passing the syngas through the dolomite bed.

Similarly, significant reduction ( $\mathrm{p}<0.05)$ was observed in the particulates concentration as well. A $41 \%$ and 57\% reduction in particulates concentration was achieved for wood chips and pine pellets, respectively.

\subsection{Effect of Temperature on Dolomite Performance}

The catalytic bed temperature was varied in $100^{\circ} \mathrm{C}$ increments from $650^{\circ} \mathrm{C}$ to $950^{\circ} \mathrm{C}$ to investigate its effect on tar removal, expressed as the concentration left in the gas. The results presented in Figure 6 shows an increase in the performance of the dolomite as bed temperature increased from $650^{\circ} \mathrm{C}$ to $950^{\circ} \mathrm{C}$, for both pine pellets and wood chips. However, after increasing the temperature beyond $850^{\circ} \mathrm{C}$, the rise in temperature did not produce any improvement on the catalyst performance. This indicates that temperatures beyond $850^{\circ} \mathrm{C}$ yield diminishing returns (with respect to tar cracking), thereby, making the overall process economically impractical.

The incremental cost of maintaining a catalyst at a higher temperature also goes up significantly due to higher heat losses at elevated temperatures. Furthermore, at temperatures higher than $1000^{\circ} \mathrm{C}$, thermal cracking of tars can take place to a certain degree purely due to the high temperatures. Considering the heating costs and cracking efficiency, catalyst bed temperatures of $800^{\circ} \mathrm{C}$ $850^{\circ} \mathrm{C}$ appear to be the ideal temperature range for the dolomite bed.

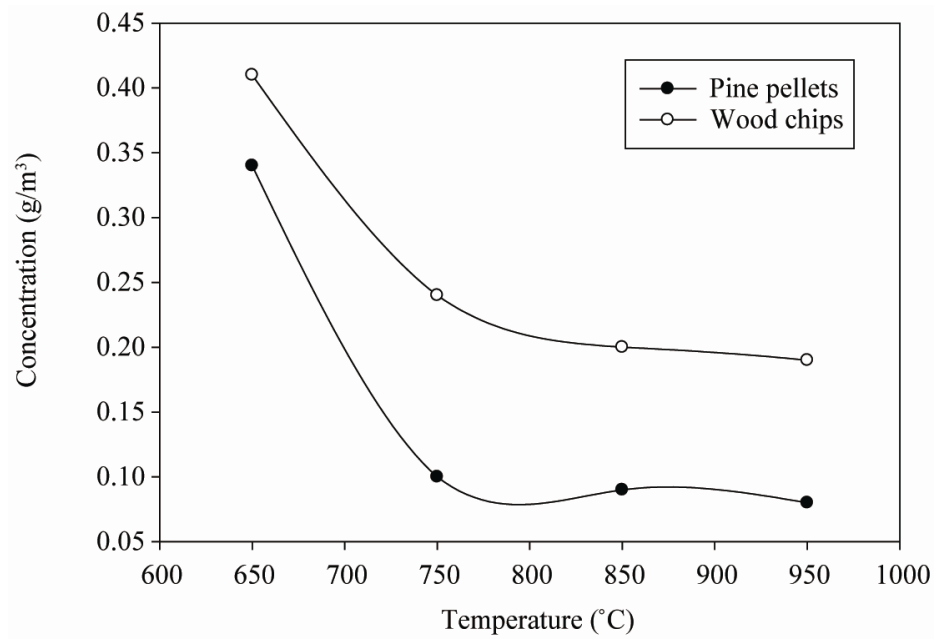

Figure 6. Performance of dolomite as bed temperature increases from $650^{\circ} \mathrm{C}$ to $950^{\circ} \mathrm{C}$ on tar removal for both pine pellets and wood chips, expressed asthe concentration left in the gas. 


\section{Conclusion}

Gasification of biomass for energy production requires effective gas cleaning techniques that removes the tars and particulates formed during process. In this study, dolomite was investigated for its tar cracking capability in a downdraft gasification system. Temperature studies indicate an optimum catalytic bed performance at $800^{\circ} \mathrm{C}$ - $850^{\circ} \mathrm{C}$. The gravimetric analysis presented in this paper is an attempt to overcome the tar and particulate problems associated with biomass gasification. Additional work is needed in order to investigate the tar cracking potential of proprietary low temperature catalysts and a possible combination of different catalytic bed reactors. A chemical analysis of the tar components and deposits on the spent catalyst (if any) is needed to better understand and design a gasification system.

\section{REFERENCES}

[1] J. Gil, M. P. Aznar, M. A. Caballero, E. Frances and J. Corella, "Biomass Gasification in Fluidized Bed at Pilot Scale with Steam-Oxygen Mixtures. Product Distribution for Very Different Operating Conditions,” Energy \& Fuels, Vol. 11, No. 6, 1997, pp. 1109-1118.

doi:10.1021/ef9602335

[2] I. Narvaez, A. Orio, M. P. Aznar and J. Corella, "Biomass Gasification with Air in an Atmospheric Bubbling Fluidized Bed. Effect of Six Operational Variables on the Quality of the Produced Raw Gas," Industrial \& Engineering Chemistry Research, Vol. 35, No. 7, 1996, pp. 2110-2120. doi:10.1021/ie9507540

[3] A. J. M. Pemen, E. J. M. van Heesch, K. Yan, S. V. B. van Paasen, K. J. Ptasinski, Z. Matyas, P. A. Huijbrechts, B. O. E. Hultermans, A. Nicoletti, P. P. M. Blom and P. Zacharias, "Experimental Program of the Pulsed Corona Tar Cracker,” Conference Paper for Pulse Power Conference. Digest of Technical Papers. 12th IEEE International, Monterey, CA, Vol. 1, 1999, pp. 515-518.

[4] J. Herguido, J. Corella and J. Gonzalezsaiz, "Steam Gasification of Lignocellulosic Residues in a Fluidized-Bed at a Small Pilot Scale-Effect of the Type of Feedstock," Industrial \& Engineering Chemistry Research, Vol. 31, No. 5, 1992, pp. 1274-1282. doi:10.1021/ie00005a006

[5] T. A. Milne, N. Abatzoglou and R. J. Evans, "Biomass Gasifier Tars: Their Nature, Formation, and Conversion,” NREL Report, NREL/TP-570-25357, NREL, Golden, CO, 1998.

[6] D. Dayton, "A Review of the Literature on Catalytic Biomass Tar Destruction,” NREL Report, NREL/TP-51032815, NREL, Golden, CO, 2002.

[7] J. Delgado, M. P. Aznar and J. Corella, "Calcined Dolomite, Magnesite, and Calcite for Cleaning Hot Gas from a Fluidized Bed Biomass Gasifier with Steam: Life and
Usefulness," Industrial \& Engineering Chemistry Research, Vol. 35, No. 10, 1996, pp. 3637-3643. doi:10.1021/ie950714w

[8] L. Devi, K. J. Ptasinski, F. Janssen, S. V. B. van Paasen, P. C. A. Bergman and J. H. A. Kiel, "Catalytic Decomposition of Biomass Tars: Use of Dolomite and Untreated Olivine,” Renewable Energy, Vol. 30, No. 4, 2005, pp. 565-587. doi:10.1016/j.renene.2004.07.014

[9] M. P. Aznar, J. Corella, J. Gil, J. A. Martin, M. A. Caballero, A. Olivares, P. Perez and E. Frances, "Biomass Gasification with Steam and Oxygen Mixtures at Pilot Scale and with Catalytic Gas Upgrading. Part I: Perform- ance of the Gasifier,” In: A. V. Bridgwater and D. G. B. Boocock, Eds., Developments in Thermochemical Bio- mass Conversion, Kluwer Academic Publishers, London, 1997, pp. 1194-1208.

[10] S. Rapagna, N. Jand, A. Kiennemann and P. U. Foscolo, "Steam-Gasification of Biomass in a Fluidised-Bed of Olivine Particles,” Biomass \& Bioenergy, Vol. 19, No. 3, 2000, pp. 187-197. doi:10.1016/S0961-9534(00)00031-3

[11] W. Y. Wang, N. Padban, Z. C. Ye, A. Andersson and I. Bjerle, "Kinetics of Ammonia Decomposition in Hot Gas Cleaning,” Industrial \& Engineering Chemistry Research, Vol. 38, No. 11, 1999, pp. 4175-4182. doi:10.1021/ie990337d

[12] S. Anis and Z. A. Zainal, "Tar Reduction in Biomass Producer Gas via Mechanical, Catalytic and Thermal Methods: A Review," Renewable \& Sustainable Energy Reviews, Vol. 15, No. 5, 2011, pp. 2355-2377. doi:10.1016/jsser.2011.02.018

[13] E. Kurkela, P. Stahlberg, J. Laatikainen and P. Simell, "Development of Simplified Igcc-Processes for BiofuelsSupporting Gasification Research at VTT,” Bioresource Technology, Vol. 46, No. 1-2, 1993, pp. 37-47. doi:10.1016/0960-8524(93)90052-D

[14] J. Corella, M. P. Aznar, J. Gil and M. A. Caballero, "Biomass Gasification in Fluidized Bed: Where to Locate the Dolomite to Improve Gasification?” Energy \& Fuels, Vol. 13, No. 6, 1999, pp. 1122-1127. doi:10.1021/ef990019r

[15] C. O. Akudo and C. S. Theegala, "Sampling and Analysis of Tars and Particulates from a Biomass Downdraft Gasifier," Conference Paper for ASABE Annual International Meeting, Minneapolis, Paper No. 074149, 17-20 June 2007, pp. 1-7.

[16] C. O. Akudo, "Quantification of Tars and Particulates from a Pilot Scale, Downdraft Biomass Gasifier,” Masters Thesis, Louisiana State University, Baton Rouge, 2008.

[17] L. Wei, "Experimental Study on the Effects of Operational Parameters of a Downdraft Gasifier,” Masters Thesis, Mississippi State University, Starkville, 2005.

[18] C. M. Kinoshita, Y. Wang and J. Zhou, "Tar Formation under Different Biomass Gasification Conditions,” Journal of Analytical and Applied Pyrolysis, Vol. 29, No. 2, 1994, pp. 169-181. doi:10.1016/0165-2370(94)00796-9 